\title{
PENGARUH PERLAKUAN KIMIA SERAT ALAM RAMIE TERHADAP KEKUATAN TARIK SERAT TUNGGAL
}

\author{
Oleh \\ I Nyoman Pasek Nugraha \\ Jurusan Teknik Elektronika, FTK, UNDIKSHA
}

\begin{abstract}
ABSTRAK
Proses Penelitian ini bertujuan untuk mengetahui pengaruh perlakuan kimia pada serat alam rami terhadap kekuatan tarik serat tunggal. Serat mendapat perlakuan $\mathrm{NaOH}$ dengan variasi konsentrasi dan waktu disusul oleh proses pembersihan dengan $\mathrm{H}_{2} \mathrm{O}_{2}$ dan xylene serta proses sizing menggunakan natrium silika dengan variasi konsentrasi dan waktu. Hasil penelitian menunjukkan bahwa perlakuan sizing meningkatkan kekuatan tarik serat sampai 25\% dibandingkan dengan tanpa perlakuan. Kekuatan tarik serat maksimum sebesar $598 \mathrm{MPa}$ didapatkan dari perlakuan $5 \% \mathrm{NaOH}$ selama 2 jam dan dilanjutkan pembersihan dengan xylene serta perlakuan sizing 30\% natrium silika selama 3 jam. Hasil penelitian ini selanjutnya digunakan sebagai acuan perlakuan awal pada serat alam rami sebagai penguat material komposit polimer.
\end{abstract}

Kata kunci : serat alam rami, sizing, $\mathrm{NaOH}, \mathrm{H}_{2} \mathrm{O}_{2}$, xylene, natrium silika, kekuatan tarik

\begin{abstract}
This study aims to determine the effect of chemical treatment on natural fiber ramie on a single fiber tensile strength. $\mathrm{NaOH}$-treated fibers by varying the concentration and time followed by the cleaning process with $\mathrm{H}_{2} \mathrm{O}_{2}$ and xylene as well as the sizing process using sodium silica by varying the concentration and time. The results showed that the treatment increases the tensile strength of fiber sizing up to $25 \%$ compared with no treatment. Maximum fiber tensile strength $598 \mathrm{MPa}$ obtained from the treatment of $5 \% \mathrm{NaOH}$ for 2 hours and continue cleaning with xylene and sizing treatment of $30 \%$ sodium silica for 3 hours. The study was then used as a reference pretreatment on natural hemp fiber polymer composites as reinforcement material.
\end{abstract}

Keywords: ramie natural fiber, sizing, $\mathrm{NaOH}, \mathrm{H}_{2} \mathrm{O}_{2}$, xylene, natrium silica, the tensile strength

\section{PENDAHULUAN}

Pengembangan dan optimalisasi serat alam sebagai media penguatan untuk material komposit polimer dewasa ini terus berlanjut. Serat alam (natural fiber) 
digunakan sebagai bahan penguat komposit plastik karena memiliki keunggulan dibandingkan dengan serat glass, diantaranya: sumber alam yang dapat diperbaharui (renewable), berlimpah, murah, ringan, non-abrasive, dapat terbiodegradasi, tidak beracun, memiliki sifat mekanik yang baik serta cocok untuk peredam akustik dan panas (Peijs, 2002).

Serat alam rami merupakan salah satu jenis serat yang tumbuh dan jumlahnya berlimpah di Indonesia tetapi belum dimanfaatkan secara optimal dalam aplikasi teknik. Serat non kayu dan non bambu memiliki peluang untuk dikembangkan sebagai material struktur melalui pemahaman sifat dan komposisinya (Olessen dan Plackett, 1999). Serat alam membutuhkan perlakuan awal sebelum digunakan sebagai media penguatan pada komposit polimer untuk menghasilkan mutu ikatan interface antara serat dengan matrik yang baik. Prosedur perlakuan awal pada serat alam menggunakan perlakuan kimia umumnya diikuti dengan proses pembersihan dan penambahan katalis (sizing) untuk memperbaiki sifat fisis dan mekanisnya.

Berdasarkan uraian tersebut diatas, maka penulis melakukan penelitian terhadap pengaruh perlakuan kimia pada serat alam rami yang meliputi perlakuan $\mathrm{NaOH}$, perlakuan pembersih xylene dan $\mathrm{H}_{2} \mathrm{O}_{2}$, dan perlakuan sizing natrium silika. Karakterisasi dilakukan dengan pengujian terhadap kekuatan tarik serat tunggal (single fiber tensile strength) dan pengamatan topografi permukaan dengan mikroskop optik digital.

Ray dkk (2000) yang meneliti perlakuan alkali pada serat jute dengan konsentrasi larutan $\mathrm{NaOH} 5 \%$ selama 0, 2, 4, 6, dan 8 jam, diperoleh kekuatan maksimum komposit jute/ vinylester melalui waktu perlakuan selama 4 jam dengan $5 \% \mathrm{NaOH}$ pada $30^{\circ} \mathrm{C}$. Eichhorn dkk (2001) menyatakan bahwa perlakuan alkali dengan konsentrasi larutan $8 \% \mathrm{NaOH}$ pada serat jute dapat pula mengubah topografi permukaan serat dan struktur kristalnya. Perlakuan alkali juga menunjukkan peningkatan kekuatan tarik pada komposit sisal/polyester sebesar 20\% (Mishra dkk, 2002). 
Panigrahi dkk (2003); Wang dkk (2003) menyatakan bahwa perlakuan sodium hidroksida $(\mathrm{NaOH})$ dilanjutkan dengan pembersihan dengan hidrogen peroksida $\left(\mathrm{H}_{2} \mathrm{O}_{2}\right)$ dan xylene dapat meningkatkan perekatan antara molekul, wetting, tegangan permukaan, porositas dan kekasaran permukaan dari serat flax. Media xylene juga dapat meningkatkan pelekatan interfase, wetability, dan kompabilitas antara serat dan matrik (Velde dan Kiekens, 1999). Berger dkk (1999) dalam penelitiannya menggunakan perlakuan $\mathrm{NaSi}$ untuk memodifikasi permukaan serat serat kenaf/cotton dan dihasilkan permukaan serat yang lebih halus dibandingkan dengan yang tanpa perlakuan.

\section{Serat Tumbuhan}

Serat tumbuhan (Plant fibers) adalah kelompok serat alam yang dihasilkan dari tumbuh-tumbuhan. Klasifikasi serat tumbuhan dan beberapa sifat mekanis serat ditunjukkan pada gambar 1 berikut ini.

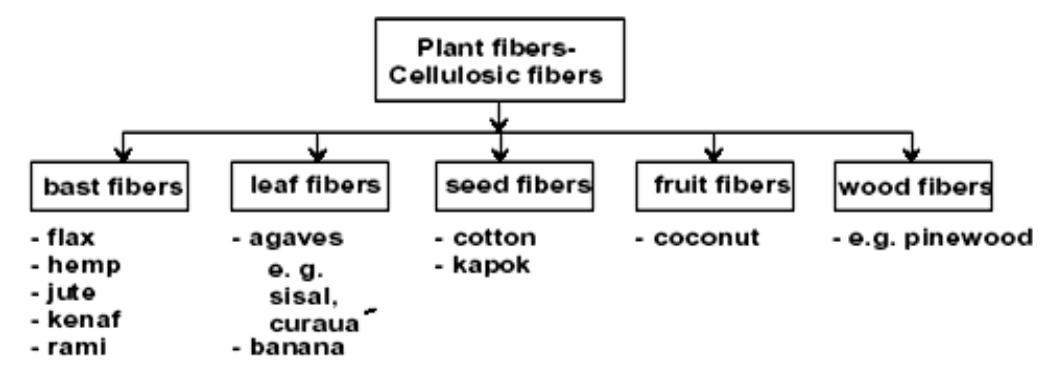

Gambar 1. Klasifikasi dari serat tumbuhan (Schuh, 1999)

Sifat mekanis serat alam banyak dipengaruhi oleh kandungan selulosa (Rowell dan Han, 2000). Serat alam rami (Boehmeria Nivea) memiliki kandungan selulosa dan modulus elastisitas yang relatif paling tinggi jika dibandingkan dengan serat alam yang lain, sehingga memungkinkan untuk digunakan sebagai media penguatan untuk komposit polimer. Komposisi kimia serat alam rami ditunjukkan pada tabel 1 di bawah ini. 
Tabel 1. Komposisi kimia dari serat alam rami (Bruhlmann dkk, 1994)

\begin{tabular}{|c|c|c|c|c|c|c|}
\hline Kandungan & Cellulose & $\begin{array}{c}\text { Hemi- } \\
\text { cellulose }\end{array}$ & Pectin & Lignin & Wax & $\begin{array}{c}\text { Water } \\
\text { Soluble }\end{array}$ \\
\hline Persentase & $68,8 \%$ & $13,1 \%$ & $1,9 \%$ & $0,6 \%$ & $0,3 \%$ & $5,5 \%$ \\
\hline
\end{tabular}

\section{Perlakuan Kimia Serat (Fiber Chemical Treatment)}

Serat alam membutuhkan perlakuan awal sebelum digunakan sebagai media penguatan pada komposit polimer untuk menghasilkan mutu ikatan interface antara serat dengan matrik yang baik secara kualitatif dan kuantitatif (Drzall ,1999; Rowell dan Han, 2000; Mohanty dkk, 2001). Perlakuan awal dengan bahan kimia yang sering digunakan adalah $\mathrm{NaOH}$. Perlakuan ini bertujuan untuk menghilangkan kandungan pectin, lignin dan hemiselulosa yang menutupi serat sehingga dapat digunakan untuk proses selanjutnya. Media pembersih sodium hidroksida $\left(\mathrm{H}_{2} \mathrm{O}_{2}\right)$ dan xylene digunakan untuk membersihkan sisa perlakuan $\mathrm{NaOH}$ pada serat (Panigrahi dkk, 2003; Wang dkk, 2003). Selain sebagai pembersih, xylene juga digunakan sebagai pelarut (solvent) dan berfungsi untuk meningkatkan pelekatan interfase, wetability, dan kompabilitas antara serat dan matrik (Velde dan Kiekens, 1999). Perlakuan sizing merupakan salah satu upaya untuk memodifikasi permukaan permukaan serat. Natrium silika dapat meningkatkan kekuatan dan ketahanan serat terhadap udara, uap air, serta cuaca dalam jangka waktu yang cukup lama (Berger dkk, 1999).

\section{Kekuatan Tarik Serat Tunggal (Single Fiber Tensile Strength)}

Untuk menghitung Kekuatan tarik serat digunakan persamaan :

$$
\sigma=\frac{F}{A}
$$

dimana:

$$
\begin{aligned}
\sigma & =\text { Kekuatan tarik, } \mathrm{Pa} \\
F & =\text { Beban untuk memutuskan serat, } \mathrm{N} \\
\mathrm{A} & =\text { Luas serat rata-rata, } \mathrm{m}^{2}
\end{aligned}
$$

Luasan serat rata-rata dicari menggunakan persamaan: 


$$
A=\frac{\sum a_{f} \times 10^{6}}{N\left(M_{f}\right)^{2}}
$$

dimana:

$$
\begin{aligned}
A & : \text { Luas serat rata-rata, } \mathrm{m}^{2} \\
a_{f} & : \text { Luas satu daerah serat, } \mathrm{m}^{2} \\
N & : \text { Jumlah pengamatan serat } \\
M_{f} & : \text { Faktor skala mikroskop }
\end{aligned}
$$

\section{METODE PENELITIAN}

\section{Bahan}

Bahan yang digunakan dalam penelitian ini adalah serat alam rami (Boehmeria Nivea) jenis pujon X yang berasal dari Garut dan telah melalui proses dekortikasi.

\section{Alat Penelitian}

- Universal testing machine

- Mikroskop optik digital

- Timbangan digital

- Oven pemanas listrik

\section{Jalan Penelitian}

1. Serat rami yang telah didekortikasi dipotong dengan panjang $\mathrm{L}=20 \mathrm{~cm}$.

2. Perlakuan larutan alkali dengan konsentrasi larutan $\mathrm{NaOH}$ sebesar $0,5,10$, dan $15 \%$ pada temperatur $100^{\circ} \mathrm{C}$ selama 1 dan 2 jam, selanjutnya dilakukan pencucian dengan air sampai $\mathrm{ph}=7$ dan kemudian dikeringkan.

3. Perlakuan dengan larutan $\mathrm{H}_{2} \mathrm{O}_{2}$ dan xylene (no.batch: 0105D-Brataco Chemika Bandung) selama 1 jam dan dilakukan pencucian dengan air sampai $\mathrm{ph}=7$ kemudian dikeringkan. 
4. Proses pengeringan dengan oven pemanas pada temperatur $110^{\circ} \mathrm{C}$ selama 1 jam lalu serat disimpan dan diberi desikator silika gel.

5. Perlakuan kimia natrium silika (no. Batch: J127/05-Brataco Chemika Bandung) dengan konsentrasi sebesar 10, 20, dan 30\% selama 1 dan 3 jam

6. Serat dikeringkan dalam oven dengan temperatur $60^{\circ} \mathrm{C}$ selama 1 jam.

7. Pengujian kekuatan tarik serat tunggal dengan universal testing machine menggunakan standar spesimen ASTM D 3379 dan pengamatan topografi permukaan dengan mikroskop optik digital.

\section{HASIL DAN PEMBAHASAN}

\section{Pengaruh Perlakuan $\mathrm{NaOH}$}

Hasil pengujian kekuatan tarik serat alam rami dengan perlakuan $\mathrm{NaOH}$ ditunjukkan pada gambar, terlihat bahwa terjadi peningkatan kekuatan tarik pada waktu perlakuan selama 2 jam dengan konsentrasi $5 \% \mathrm{NaOH}$ dan kemudian terjadi penurunan kekuatan tarik serat ketika konsentrasi larutan bertambah. Hal ini berbeda dengan waktu perlakuan selama 1 jam yang meningkat kekuatan tariknya sampai pada konsentrasi $10 \% \mathrm{NaOH}$ dan baru kemudian menurun dengan bertambahnya konsentrasi larutan. Kekuatan tarik tertinggi diperoleh pada perlakuan $5 \% \mathrm{NaOH}$ selama 2 jam sebesar 477,5 Mpa.

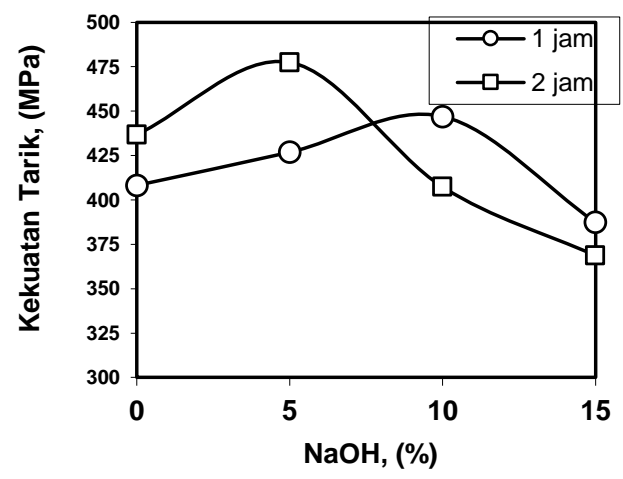

Gambar 3. Grafik hasil uji kekuatan tarik serat dengan variasi konsentrasi $\mathrm{NaOH}$ 


\section{Pengaruh Perlakuan $\mathrm{H}_{2} \mathrm{O}_{2}$ dan xylene}

Hasil pengujian kekuatan tarik serat alam rami dengan variasi perlakuan media pembersih ditunjukkan pada gambar 4 , terlihat bahwa perlakuan dengan media pembersih xylene menunjukkan kekuatan tarik yang lebih tinggi dibandingkan dengan $\mathrm{H}_{2} \mathrm{O}_{2}$. Perlakuan xylene menghasilkan kekuatan tarik maksimum sebesar 484 MPa. Ini berarti peningkatan kekuatan tarik pada perlakuan xylene tidak signifikan terhadap serat yang tanpa perlakuan.

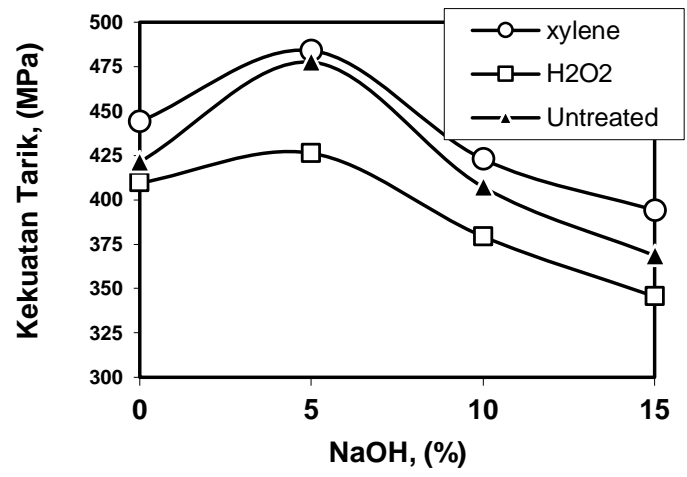

Gambar 4. Grafik hasil uji kekuatan tarik serat dengan variasi proses pembersihan

\section{Pengaruh Perlakuan natrium silika}

Hasil pengujian tarik serat alam rami dengan variasi konsentrasi larutan natrium silika dan lama waktu pencelupan ditunjukkan pada gambar 5 .

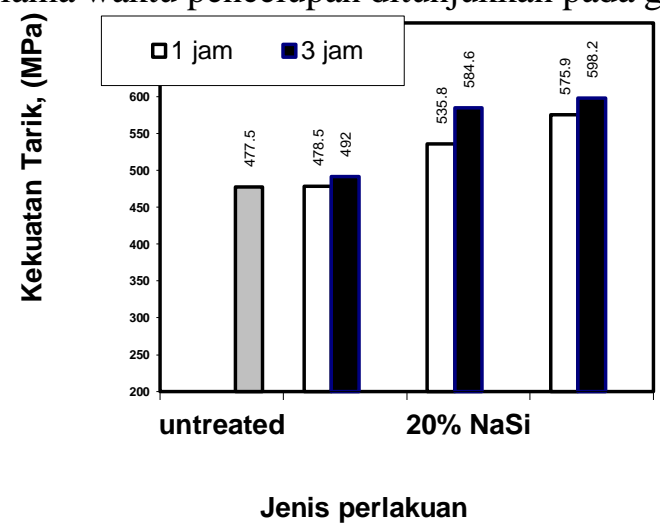

Gambar 5. Grafik hasil uji kekuatan tarik serat dengan variasi perlakuan sizing 
Dari grafik di atas terlihat bahwa terjadi peningkatan kekuatan tarik serat dengan meningkatnya konsentrasi larutan natrium silika seiring dengan lamanya waktu pencelupan. Perlakuan sizing dengan konsentrasi larutan natrium silika 30\% selama 3 jam menunjukkan kekuatan tarik maksimum sebesar 598,2 MPa. Peningkatan yang terjadi akibat perlakuan sizing natrium silika dengan konsentrasi larutan 30\% selama 3 jam sekitar 25\% jika dibandingkan dengan tanpa perlakuan.

\section{Topografi Permukaan}

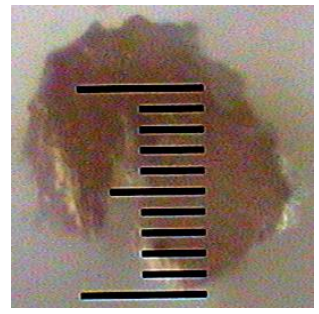

$100 \mathrm{X}$

Gambar 6. Perlakuan Kimia

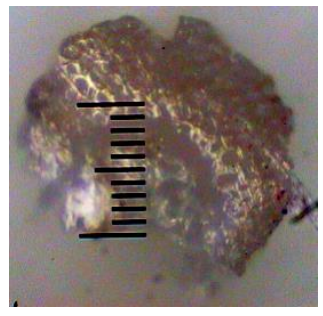

$50 X$

Gambar 7. Tanpa perlakuan

Gambar 6 menunjukkan serat dengan perlakuan kimia tampak lebih bersih dan memiliki diamater yang lebih kecil dibandingkan dengan serat tanpa perlakuan (gambar 7). Hal ini disebabkan karena perlakuan kimia akan menghilangkan lignin dan pektin serta memisahkan filamen-filamen serat sehingga menjadi lebih bersih dan memiliki diameter yang lebih kecil dengan struktur yang lebih padat.

\section{PENUTUP}

Dari uraian pembahasan di atas, dapat ditarik beberapa simpulan berikut ini :

1. Perlakuan $\mathrm{NaOH}$ menghasilkan kekuatan tarik tertinggi pada konsentrasi $5 \%$ $\mathrm{NaOH}$ selama 2 jam.

2. Perlakuan xylene menghasilkan kekuatan tarik yang lebih tinggi dibandingkan dengan perlakuan $\mathrm{H}_{2} \mathrm{O}_{2}$. 
3. Perlakuan natrium silika meningkatkan kekuatan tarik serat sebesar $25 \%$ dibandingkan tanpa perlakuan.

4. Kekuatan tarik maksimum sebesar 598,2 $\mathrm{MPa}$ diperoleh melaui proses perlakuan $\mathrm{NaOH} 5 \%$ selama 2 jam diikuti dengan perbersihan xylene serta perlakuan sizing natrium silika $30 \%$ selama 3 jam.

5. Topografi permukaan serat dengan perlakuan kimia lebih bersih dan memiliki diameter yang lebih kecil dengan struktur yang lebih padat dibandingkan dengan tanpa perlakuan.

\section{DAFTAR PUSTAKA}

Berger, P.B., Hoven, T.V., Ramaswamy, G.N., Kimmel, L. and Boylston, E., 1999, Textile Technology Cotton/Kenaf Fabrics: a Viable Natural Fabric, The Journal of Cotton Science, Vol. 3, pp. 60-70

Bruhlmann, F., Kim, K.S., Zimmerman, W. and Fiechter, A., 1994, Pectinolytic Enzimes from Actynomycetes for the Degumming of Ramie Bast Fiber, Applied and Evironmental Microb, Vol.60 (6), pp.2107-2112

Drzal, L.T., 1999, Chemical, Physical and Mechanical Method of Fiber-Matrix Adhesion and Interface Characterization in Composite, Electron Beam Curing Workshop, Oak ridge

Eichorn, S.J., Zafeiropoulus, C.A.B.N., Ansel, L.Y.M.M.P., Entwistle, K.M., Escamilla, P.J.H.F.G.C., Groom, L., Hill, M.H.C., Rials, T.G. and Wild, P.M., 2001, Review Current International Research into Cellulosic Fibers and Composites, Journal of Materials Science, Vol. 36, pp. 21 07-2131

Mishra, S., Misra, M., Tripathy, S.S., Nayak, S.K. and Mohanty, A.K., 2002, the Influence of Chemical Surface Treatment Modification on the Performance of Sisal-Polyester Biocomposites, Polymer Composites Vol. 23, No. 2, pp. 164-170

Olessen, P.O. and Plackett, D.V., 1999, Perspective on the Performance of Natural Plant Fibers, Natural Fibers Performance Forum, Copenhagen

Panigrahi, S., Powell, T., Wang, B., Tabil, L.G., Crerar, W. J. and Sokansanj, S., 2003, The Effect of Chemical Pretreatments on Flax Fiber Biocomposites, ASAE Meeting Presentation, Paper No. RRV03-0018 
Peijs, T., 2002, Composites Turn Green!, e-Polymers 2002. No. T_002, http://www.e-polymers.org

Ray, D., Sarkar, B.K., Rana, A.K. and Bose, N.R., 2001, Effect of Alkali Treated Jute Fibers on Composites Properties, Bulletin of Materials Science, Vol. 24, No. 2, pp. 129-135

Rowell, R.M. and Han, J.S., 2000, Characterization and Factors Effecting Fiber Properties, Natural Polymer and Agrofiber Composite, Brasil

Schuh, T.G., 1999, Renewable Materials for Automotive Applications, DaimlerChrysler AG, Stuttgart

Velde, K.V. and Kiekens, P., 1999, Wetability of Natural Fibres Used as Reinforcement for Composites, Die Angewandte Makromolekulare Chemie vol. 272, 1999, pp.87-93 